\title{
Conversion Process of Amorphous Si-Al-C-O Fiber into Nearly Stoichiometric SiC Polycrystalline Fiber
}

\author{
Ryutaro Usukawa, Hiroshi Oda*, and Toshihiro Ishikawa ${ }^{\dagger}$ \\ Tokyo University of Science, Yamaguchi 756-0884, Japan \\ *Ube Industries, Ltd., Yamaguchi 755-8633, Japan
}

(Received September 1, 2016; Revised October 18, 2016; Accepted October 18, 2016)

\begin{abstract}
Tyranno SA (SiC-polycrystalline fiber, Ube Industries Ltd.) shows excellent heat-resistance up to $2000^{\circ} \mathrm{C}$ with relatively high mechanical strength. This fiber is produced by the conversion process from a raw material (amorphous Si-Al-C-O fiber) into SiCpolycrystalline fiber at very high temperatures over $1500^{\circ} \mathrm{C}$ in argon. In this conversion process, the degradation reaction of the amorphous Si-Al-C-O fiber accompanied by a release of CO gas for obtaining a stoichiometric composition and the subsequent sintering of the degraded fiber proceed. Furthermore, vaporization of gaseous SiO, phase transformation and active diffusion of the components of the Si-Al-C-O fiber competitively occur. Of these changes, vaporization of the gaseous $\mathrm{SiO}$ during the conversion process results in an abnormal SiC-grain growth and also leads to the non-stoichiometric composition. However, using a modified Si-Al-C-O fiber with an oxygen-rich surface, vaporization of the gaseous $\mathrm{SiO}$ was effectively prevented, and then consequently a nearly stoichiometric $\mathrm{SiC}$ composition could be obtained.
\end{abstract}

Key words : SiC polycrystalline fiber, Tensile strength, Production process

\section{Introduction}

$\mathrm{U}$ to now, lots of inorganic fibers have been developed and commercialized. Of these, SiC fibers show relatively good mechanical strengths up to very high temperatures over $1000^{\circ} \mathrm{C}^{1-4)}$ Accordingly, active research and development on various composite materials using the $\mathrm{SiC}$ fibers have been conducted. ${ }^{5-7)}$ The first developed SiC-based fibers have been produced in the middle 1960s by chemical vapor deposition onto tungsten or carbon filament core. However, as these types of SiC-based fiber had a large diameter, their applications were limited by their difficulties for use. After that, SiC-based fibers with small diameters of about 10 micron meters were synthesized from organo-silicon polymer. This type of fiber was classified into a polymer-derived SiC fiber. The first polymer-derived $\mathrm{SiC}$ fiber was synthesized from polycarbosilane by Professor Yajima in the middle 1970s. ${ }^{8)}$ After that, many types of polymer-derived SiC fibers have been developed and commercialized. ${ }^{3,4)}$ These SiC fibers can show good mechanical strength and oxidation-resistance up to very high temperatures over $1000^{\circ} \mathrm{C}$. Of these SiC fibers, stoichiometric SiCpolycrystalline fibers (Tyranno SA, Hi-Nicalon Type S, and so on) have an excellent heat-resistance up to $2000^{\circ} \mathrm{C}^{9-11)}$ Therefore, representative aircraft engine manufacturers are

${ }^{\dagger}$ Corresponding author : Toshihiro Ishikawa

E-mail : ishikawa@rs.tusy.ac.jp

Tel : +81-836-88-4564 Fax : +81-836-88-4564 expecting actual applications of the SiC-polycrystalline fibers for jet engines and land-based gas turbines in the near future as the $\mathrm{SiC} / \mathrm{SiC}$ composite materials. By the way, the mechanical properties of the composite materials are dominated by the fiber's strength. Hence, to extend the application field, increase in the mechanical strengths of these fibers is eagerly required. And also, the mechanical strength of the fiber has been found to be strongly dominated by defects contained in each fiber filament. ${ }^{1)}$ Actually, existence of some defects (residual carbon, and so on) has been confirmed. ${ }^{12,13)}$ Accordingly, to increase the fiber's strength, it's very important to decrease the residual defects during the production process. Tyranno SA (produced by Ube Industries, Ltd.) is synthesized by a conversion process from an amorphous Si-Al-C-O fiber into SiC-polycrystalline fiber. ${ }^{9)}$ In this conversion process, a degradation reaction of the amorphous Si-Al-C-O fiber and the subsequent sintering of the degraded fiber proceed. The degradation reaction is sensitively affected by the following factors: (a) SiO-gas partial pressure, (b) CO-gas partial pressure, (c) Heating rate and degradation temperature, (d) Argon gas flow. Accordingly, to obtain the desirable crystalline structure, we have to strictly control the reaction conditions during the conversion process. In this paper, lots of changes, which occur during the degradation reaction of the amorphous Si$\mathrm{Al}-\mathrm{C}-\mathrm{O}$ fiber and the subsequent sintering of the degraded fiber, will be described in detail, and also a new idea for obtaining the denser structure will appear. 


\section{Experimental Procedure}

\subsection{Basic production process of SiC-polycrystalline fiber (Tyranno SA)}

Tyranno SA is manufactured by further heat-treatment of the amorphous Si-Al-C-O fiber, which is synthesized from polyaluminocarbosilane, and has been commercialized by Ube Industries Ltd. The basic production process is shown in Fig. 1.

The precursor polymer for preparing Tyranno SA was a polyaluminocarbosilane synthesized by a reaction of polycarbosilane with tetra-butoxyaluminum at $300^{\circ} \mathrm{C}$ in nitrogen atmosphere. A spun fiber was obtained by meltspinning of the polyaluminocarbosilane, and then the spun fiber was cured at around $200^{\circ} \mathrm{C}$ in air. The cured fiber was fired at around $1300^{\circ} \mathrm{C}$ in nitrogen atmosphere to obtain the amorphous Si-Al-C-O fiber. The Si-Al-C-O fiber was composed of $\mathrm{SiC}$ fine crystals, oxide phases (estimated forms: $\mathrm{SiO}_{2}, \mathrm{AlO}_{\mathrm{x}}$ ), and excess carbons as can be seen from Fig. 1 . By the way, as mentioned above, for preparing the Si-Al-C$\mathrm{O}$ fiber we used polyaluminocarbosilane which was synthesized by the reaction of polycarbosilane and tetra-butoxyaluminum, and then we estimated that the aluminum existed as some oxide forms in the Si-Al-C-O fiber. In the next step, the amorphous Si-Al-C-O fiber was heat-treated up to around $1500^{\circ} \mathrm{C}$ in argon gas atmosphere. During the heat-treatment, by the existence of the oxide phase and excess carbon in the fiber, the amorphous Si-Al-C-O fiber was degraded accompanied by the release of $\mathrm{CO}$ gas to obtain a porous degraded fiber. The porous degraded fiber was composed of a nearly stoichiometric $\mathrm{SiC}$ composition containing small amount of aluminum. In this case, since a part of the aluminum contained in the amorphous Si-Al-C-O fiber might be disappeared as some oxide materials during the heat-treatment process, consequently the very small amount of aluminum (less than $1 \mathrm{wt} \%$ ) was contained in the degraded fiber. By the existence of the small amount of aluminum, at the next step, an effective sintering proceeded in each degraded filament composed of the nearly stoichiometric $\mathrm{SiC}$ crystals during further heat-treatment up to $2000^{\circ} \mathrm{C}$ in argon atmosphere. And then, the dense SiC-polycrystalline fiber (Tyranno SA) was obtained.

\subsection{Research on the heating condition and charac- terization of the fibers}

Research on the heat-treatment (degradation reaction and sintering) of the Si-Al-C-O fiber was performed using "Super High Temperature Inert Gas Furnace (NEWTONIAN Pascal-40, Produced by NAGANO)" under argon gas flow $(1 \mathrm{~L} / \mathrm{min}$ ). The size of the heating zone (made of graphite and $\mathrm{C} / \mathrm{C}$ composites) is $35 \mathrm{~mm}$ in diameter and $40 \mathrm{~mm}$ in height. The programing rate and the maximum temperature were $400^{\circ} \mathrm{C} / \mathrm{min}$ and $2000^{\circ} \mathrm{C}$, respectively.

The surface and cross section of the obtained fibers were observed using a field emission scanning electron microscope (FE-SEM), model JSM-700F (JEOL, Ltd.). Parts of surface region and inside of the several samples were sharpened by an etching machine using focused ion beam (FIB), and then the fine structures were observed by the transmission electron microscope (TEM), model JEM-2100F (JEOL, Ltd.).

Auger electron spectroscopy (AES) depth profiles of $\mathrm{Si}, \mathrm{Al}$, $\mathrm{C}$, and $\mathrm{O}$ were obtained using an ULVAC PHI SMART-200 operating at $3 \mathrm{kV}$.

\section{Results and Discussion}

\subsection{Possible changes during the degradation and sintering processes}

As mentioned before, SiC-polycrystalline fiber (Tyranno $\mathrm{SA}$ ) was synthesized by a conversion process from an amorphous Si-Al-C-O fiber into the SiC-polycrystalline fiber at very high temperatures up to $2000^{\circ} \mathrm{C}$ in argon atmosphere. As can be seen from Fig. 2, the Si-Al-C-O fiber was composed of oxide phases (estimated forms: $\mathrm{SiO}_{2}, \mathrm{AlO}_{\mathrm{x}}$ ), $\mathrm{SiC}$ fine crystals, and excess carbons. As long as both oxide phase

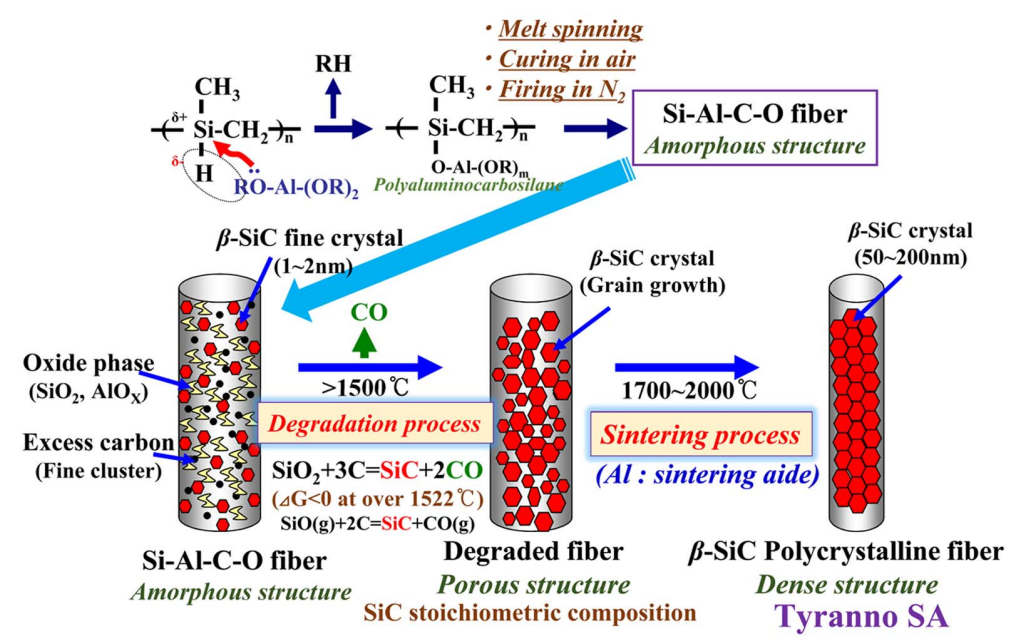

Fig. 1. Basic production process of the SiC-polycrystalline fiber (Tyranno SA). 


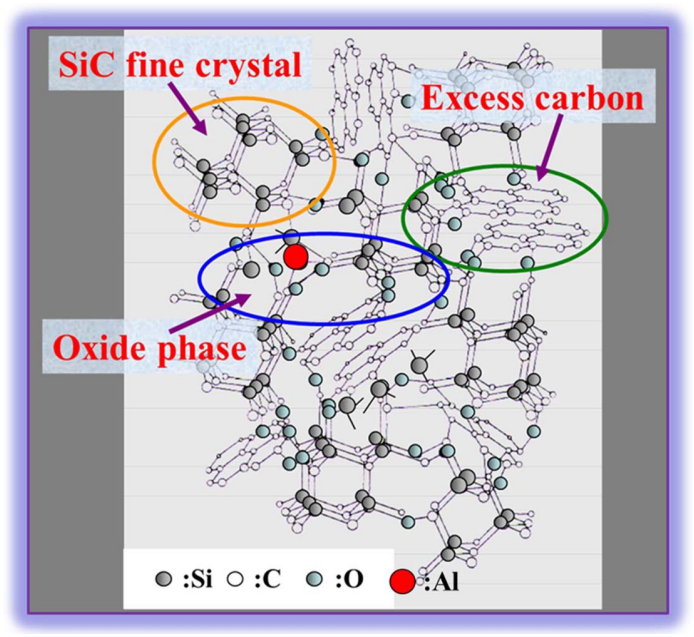

Fig. 2. Schematic fine structure of the Si-Al-C-O fiber.

and excess carbon exist, the following reaction proceeds at temperatures over $1522^{\circ} \mathrm{C}$.

$$
\mathrm{SiO}_{2}+3 \mathrm{C}=\mathrm{SiC}+2 \mathrm{CO}(\mathrm{g})\left(\Delta \mathrm{G}<0 \text { over } 1522^{\circ} \mathrm{C}\right)
$$

In this case, the behavior of gaseous $\mathrm{SiO}$ generated from the oxide phase has to be also considered. That is to say, the partial pressure of the $\mathrm{SiO}$ gas remarkably appears over $1100^{\circ} \mathrm{C}$. And also, as the $\mathrm{SiO}$ gas shows very high reactivity with carbon, the following reaction easily proceeds.

$$
\begin{aligned}
& \mathrm{SiO}(\mathrm{g})+2 \mathrm{C}=\mathrm{SiC}+\mathrm{CO}(\mathrm{g}) \\
& (\Delta \mathrm{G}<0 \text { at all temperature ranges })
\end{aligned}
$$

Both reactions are actually degradation reactions of the amorphous Si-Al-C-O fiber. However, as can be seen from these equations, these degradation reactions are very important for obtaining a nearly stoichiometric $\mathrm{SiC}$ composition. Furthermore, as the degraded fiber contains small amount of aluminum, the $\mathrm{SiC}$ crystals constructing the degraded fiber show a solid-phase sintering ability to obtain a densified structure at higher temperatures. ${ }^{9)}$ These possible changes are summarized in Fig. 3. As shown in Fig. 3, these temperature-regions can be divided into four zones.

Of these four zones, in the first zone $\left(\sim 1450^{\circ} \mathrm{C}\right)$, a vapor pressure of $\mathrm{SiO}$ gas remarkably appears over $1100^{\circ} \mathrm{C}$ as can be seen from Fig. 4. And also, this gaseous $\mathrm{SiO}$ reacts with the excess carbon contained in each Si-Al-C-O filament accompanied by the release of $\mathrm{CO}$ gas. These changes can be understood from the calculation results shown in Fig. 4. Furthermore, in this case, we have to consider a vaporization of this gaseous $\mathrm{SiO}$ from each $\mathrm{Si}-\mathrm{Al}-\mathrm{C}-\mathrm{O}$ filament. Because, consequently it leads to increase in the residual carbon after the degradation reaction. The image of these changes is schematically shown in Fig. 5.

In the second zone $\left(1450^{\circ} \mathrm{C} \sim 1522^{\circ} \mathrm{C}\right)$, the vapor pressure of gaseous $\mathrm{SiO}$ is remarkably increased. And also, in this temperature region, the diffusion rate of the excess carbon con-

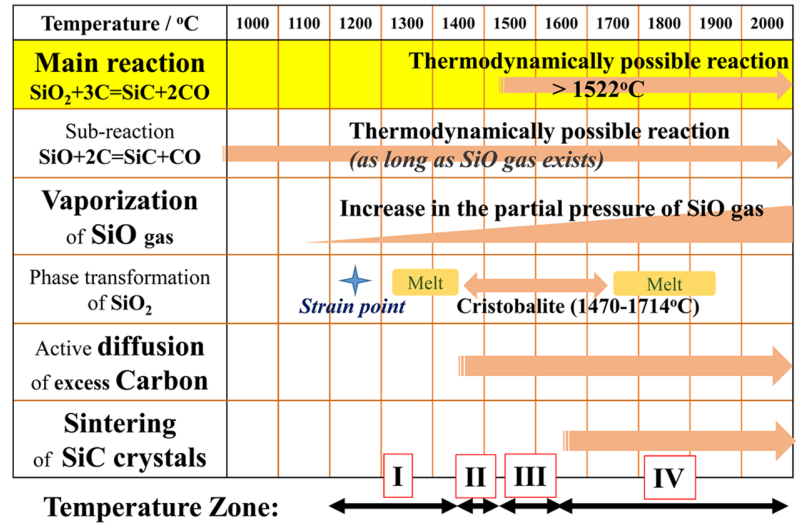

Fig. 3. Possible changes during the heat-treatment process up to $2000^{\circ} \mathrm{C}$

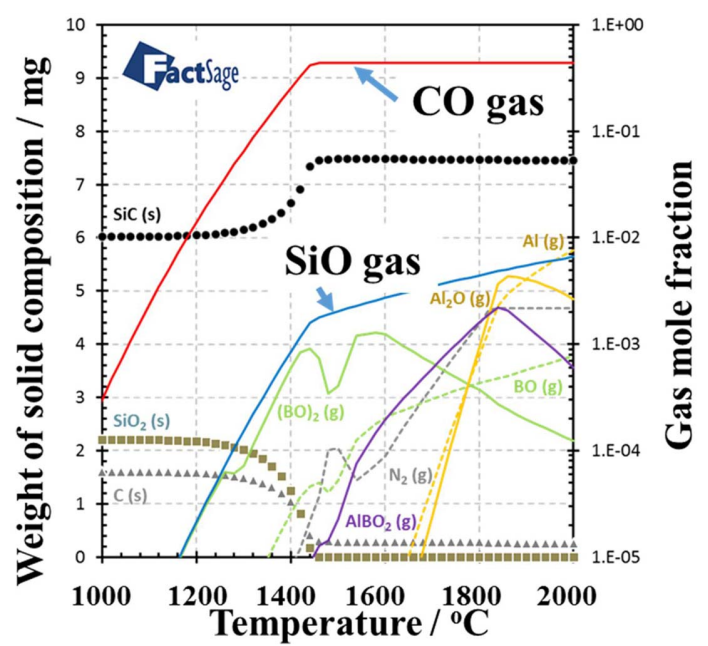

Fig. 4. Changes in the components during the heat-treatment process.

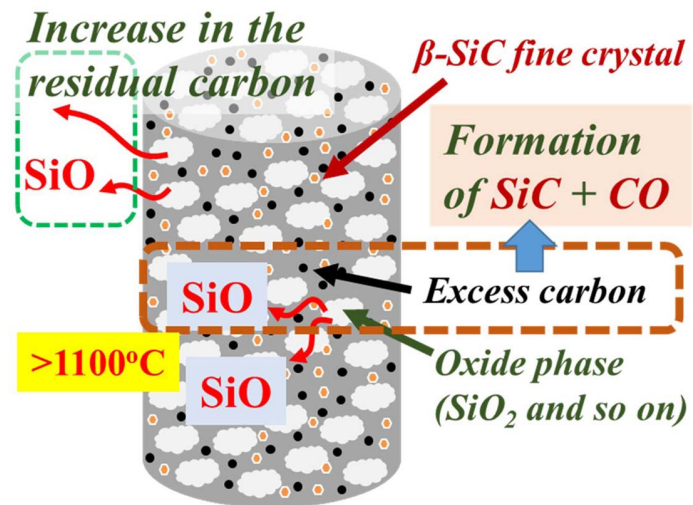

amorphous Si-Al-C-O fiber

Fig. 5. Schematic changes in the first temperature zone.

tained in each Si-Al-C-O filament is increased. Accordingly, unless we strictly control these phenomena, undesirable reaction between the $\mathrm{SiO}$ gas and the diffused excess carbon proceed on the surface region. These are undesirable changes. Because, by these undesirable changes an abnormal SiC-grain growth occurs on the surface region. This is 
closely related to the surface roughness of the obtained SiCpolycrystalline fiber. So, we have to strictly control these changes.

In the third zone $\left(1522^{\circ} \mathrm{C} \sim 1650^{\circ} \mathrm{C}\right)$, the desirable main reaction $\left(\mathrm{SiO}_{2}+3 \mathrm{C}=\mathrm{SiC}+2 \mathrm{CO}\right)$ effectively proceeds accompanied by the release of $\mathrm{CO}$ gas. This reaction can lead to the stoichiometric $\mathrm{SiC}$ composition. However, in this zone, the following undesirable changes possibly occur. That is to say, the active diffusion of the excess carbon, vaporization of $\mathrm{SiO}$ gas, and the reaction of the $\mathrm{SiO}$ gas with the excess carbon on the surface region competitively occur. In this temperature zone, to obtain the nearly stoichiometric $\mathrm{SiC}$ composition, we have to strictly control the aforementioned undesirable changes.

And finally, in the fourth zone $\left(>1650^{\circ} \mathrm{C}\right)$, each $\mathrm{SiC}$ crystal constructing the degraded fiber shows sintering phenomenon in each filament by the existence of the small amount of aluminum in each $\mathrm{SiC}$ crystal as a solid solution. And then, a dense structure was obtained. As we described in the previous paper, ${ }^{9)}$ at the $\mathrm{SiC}$ grain boundary constructing the SiC-polycrystalline fiber, an obvious second phase could not be observed.

By the way, as I mentioned before, the production process of SiC-polycrystalline fiber contains lots of heat-treatment processes accompanied by the release of gaseous materials like $\mathrm{CO}$ gas and $\mathrm{SiO}$ gas. So, this type of fiber easily remains lots of defects as shown in Fig. 6. These defects possibly dominate the strength of the obtained SiC-polycrystalline fiber. Accordingly, in order to obtain the higher strength, especially, we have to strictly control the aforementioned degradation process and the sintering process.

In the above mentioned temperature zones, the first zone $\left(\sim 1450^{\circ} \mathrm{C}\right)$ is very important for the $\mathrm{SiC}$ nucleation by the reaction of gaseous $\mathrm{SiO}$ with excess carbons. To achieve the

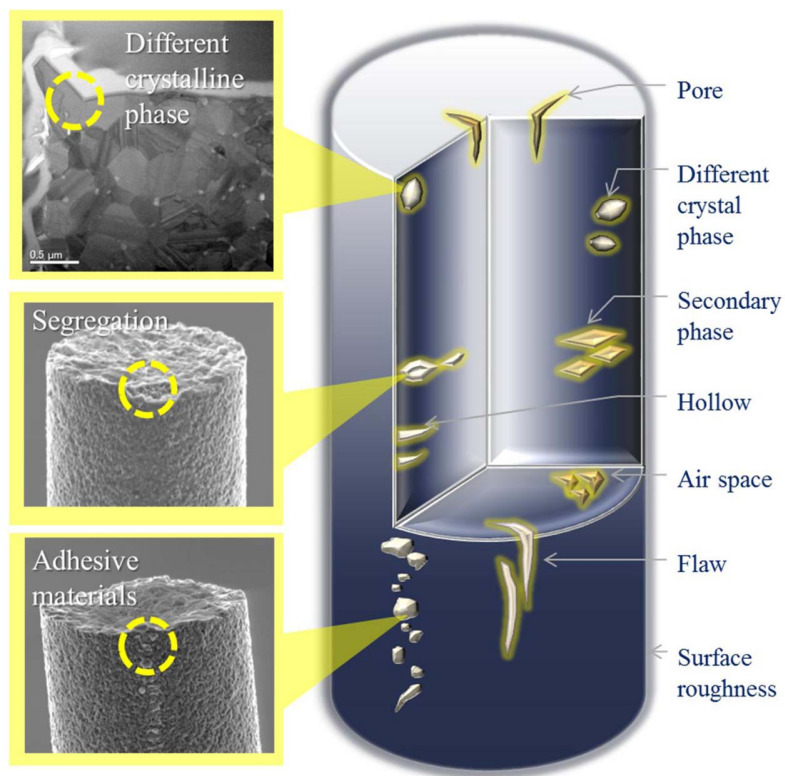

Fig. 6. Image of the residual defects in the present SiC-polycrystalline fiber. effective nucleation, we have to effectively prevent the vaporization (disappearance) of $\mathrm{SiO}$ gas from each filament. Furthermore, the vaporization of $\mathrm{SiO}$ gas possibly occur in the second zone and the third zone, too. Accordingly, it is very important to prevent the disappearance of the gaseous $\mathrm{SiO}$ from each filament during the degradation process. In the next section, we would like to propose a new idea to reduce the disappearance of gaseous $\mathrm{SiO}$ from each filament.

\subsection{A new proposal for obtaining the denser struc- ture}

As mentioned before, to prevent an abnormal SiC-grain growth and to reduce a residual carbon, we have to prevent the disappearance of gaseous $\mathrm{SiO}$ from each filament during the degradation process. To achieve this, we would like to propose a very easy approach. Fig. 7 shows our new process using a modified Si-Al-C-O fiber containing oxygen-rich surface region. This modified Si-Al-C-O fiber was prepared by a partial oxidation process. Fig. 8 shows auger electron spectroscopy (AES) depth profiles of $\mathrm{Si}, \mathrm{Al}, \mathrm{C}$, and $\mathrm{O}$ of the modified intermediate fiber. As can be seen from this figure, relatively large amount of oxygen exists in the surface region. And also, this surface region $(\sim 50 \mathrm{~nm})$ was composed of mainly silicon and oxygen with very small amount of car-

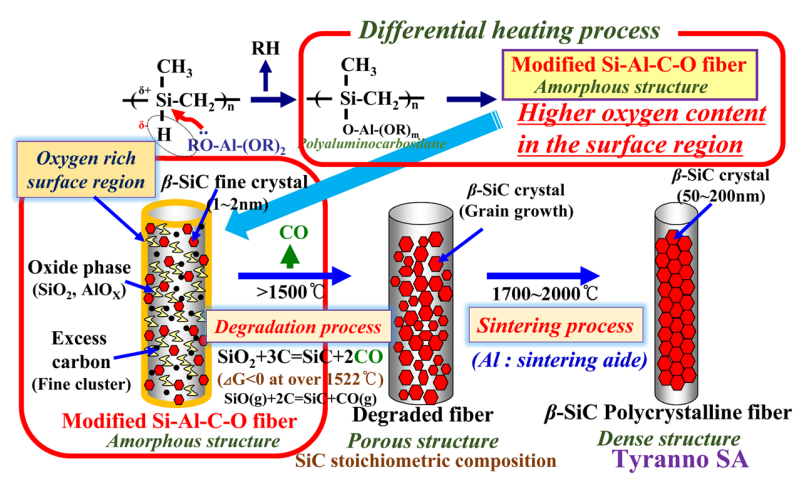

Fig. 7. One of the new approach using a modified Si-Al-C-O fiber containing oxygen-rich surface region.

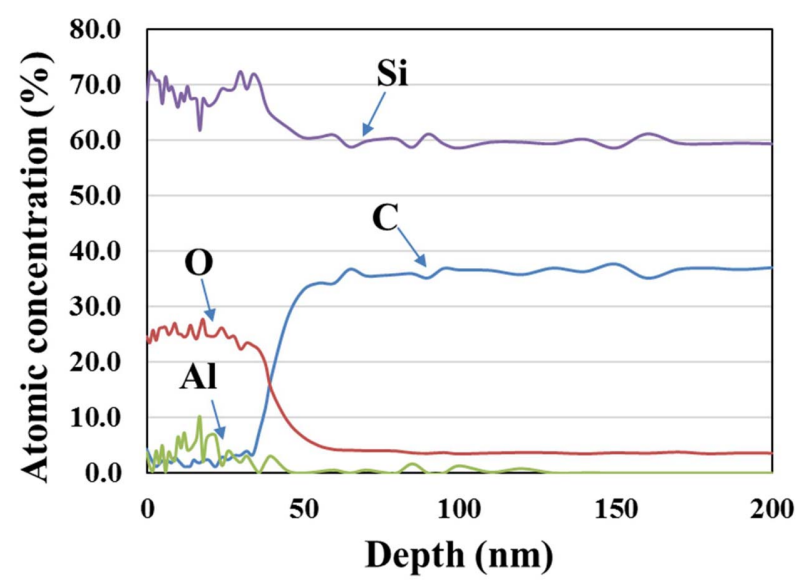

Fig. 8. Auger electron spectroscopy (AES) depth profiles of $\mathrm{Si}, \mathrm{Al}, \mathrm{C}$, and $\mathrm{O}$ of the modified intermediate fiber. 


\section{Preliminary result}

\section{Comparative fiber obtained from} conventional Si-Al-C-O fiber
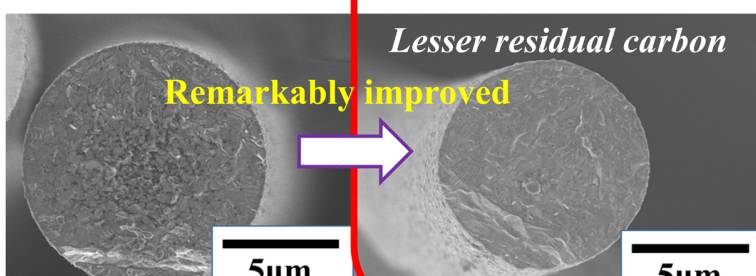

$5 \mu \mathrm{m}$
Lesser residual carbon

SiC-polycrystalline fiber with oxygen-rich surface

iproved

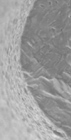

.

$5 \mu \mathrm{m}$ obtained from modified Si-Al-C-O fiber

Fig. 9. Preliminary results by the use of the modified Si-AlC-O fiber.

bon. That is to say, it was estimated that the surface layer of the modified Si-Al-C-O fiber existed as some oxide forms of silicon. Accordingly, it was considered that the oxygen-rich surface layer was relatively stable compared with the inside Si-O-C structure, and also this surface layer played an important role as a good supplier of $\mathrm{SiO}$ gas during the initial degradation processes. By the use of this type of modified Si-Al-C-O fiber, we could remarkably prevent the disappearance of $\mathrm{SiO}$ gas from the inside of each filament during the degradation reaction, and then the remarkably denser structure could be obtained as can be seen from Fig. 9 .

\section{Conclusions}

In order to produce desirable dense structure of SiC-polycrystalline fiber, we have to strictly control the degradation and sintering processes using an amorphous Si-Al-C-O fiber as a starting material. Of these, the degradation process $\left(<1650^{\circ} \mathrm{C}\right)$ was classified into three zones (I zone: $<1450^{\circ} \mathrm{C}$, II zone: $1450 \sim 1522^{\circ} \mathrm{C}$, III zone: $\left.1522 \sim 1650^{\circ} \mathrm{C}\right)$. The subsequent sintering process $\left(>1650^{\circ} \mathrm{C}\right)$ was classified into IV zone. During degradation process of the amorphous Si-Al-CO fiber, several changes proceeded stepwise and simultaneously from I zone to III zone. Of these changes, the control of a behavior of gaseous $\mathrm{SiO}$ formed from the oxide phase existing in the Si-Al-C-O fiber was most important. By the use of modified Si-Al-C-O fiber with oxygen-rich surface region, much denser structure could be obtained.

\section{Acknowledgments}

This study was funded by a Grant from NEDO (New Energy and Industrial Technology Development Organization) via Ube Industries Ltd. We gratefully acknowledge this financial support.

\section{REFERENCES}

1. T. Ishikawa and H. Oda, "Defect Control of SiC Polycrystalline Fiber Synthesized from Poly-Aluminocarbosilane," J. Eur. Ceram. Soc., 36 3657-62 (2016).

2. M. Wilson and E. Opila, "A Review of SiC Fiber Oxidation with a New Study of Hi-Nicalon SiC Fiber Oxidation," Adv. Eng. Mater., 18 [10] 1698-709 (2016).

3. O. Flores, R. K. Bordia, D. Nestler, W. Krenkel, and G. Motz, "Ceramic Fibers Based on $\mathrm{SiC}$ and SiCN Systems: Current Research, Development, and Commercial Status," Adv. Eng. Mater, 16 [6] 621-36 (2014).

4. P. Colombo, G. Mera, R. Riedel, and G. D. Soraru, "Polymer-Derived Ceramics: 40 Years of Research and Innovation in Advanced Ceramics," Ceram. Sci. Technol., 4 245320 (2013).

5. J. J. Sha, T. Nozawa, J. S. Park, Y. Katoh, and A. Kohyama, "Effect of Heat Treatment on the Tensile Strength and Creep Resistance of Advanced SiC Fibers," J. Nucl. Mater., 329 592-96 (2004).

6. K. Itatani, K. Hattori, D. Harima, M. Aizawa, and I. Okada, "Mechanical and Thermal Properties of SiliconCarbide Composites Fabricated with Short Tyranno Si-ZrC-O Fiber,” J. Mater. Sci., 36 3679-86 (2001).

7. N. R. de Esparza, N. Cocera, L. Vazquez, J. Alkorta, I. Ocana, and J. M. Sanchez, "Characterization of CVD Bonded Tyranno Fibers Oxidized at High Temperaturs," J. Am. Ceram. Soc., 97 [12] 3958-66 (2014).

8. S. Yajima, M. Omori, J. Hayashi, K. Okamura, T. Matsuzawa, and C. Liaw, "Symple Synthesis of the Continuous SiC Fiber with High Tensile Strength," Chem. Lett., 1976 [6] 551-54 (1976).

9. T. Ishikawa, Y. Kohtoku, K. Kumagawa, T. Yamamura, and T. Nagasawa, "High-Strength Alkali-Resistant Sintered SiC Fibre Stable to $2200^{\circ} \mathrm{C}$," Nature, 391 773-75 (1998).

10. M. Takeda, A. Urano, J. Sakamoto, and Y. Imai, "Microstructure and Oxidative Degradation Behavior of Silicon Carbide Fiber Hi-Nicalon Type S," J. Nucl. Mater., 258 1594-99 (1998).

11. T. Ishikawa, "Advances in Inorganic Fibers," Adv. Polym. Sci., 178 109-44 (2005).

12. C. Sauder and J. Lamon, "Tensile Creep Behavior of SiCBased Fibers with a Low Oxygen Content," J. Am. Ceram. Soc., 90 [4] 1146-56 (2007).

13. J. J. Sha, J. S. Park, T. Hinoki, and A. Kohyama,"Tensile Behavior and Microstructural Characterization of $\mathrm{SiC}$ Fibers under Loading," Mater. Sci. Eng. A, 456 72-7 (2007). 